\title{
Improved expertise in radiation protection, nuclear chemistry and geological disposal
}

\author{
Michèle Coeck ${ }^{1, *}$, Thomas Jung ${ }^{2}$, Mandy Birschwilks², Clemens Walther ${ }^{3}$, Behrooz Bazargan-Sabet ${ }^{4}$, \\ and Thomas Perko ${ }^{1}$ \\ ${ }^{1}$ SCK CEN, Boeretang 200, 2400 Mol, Belgium \\ 2 Bundesamt für Strahlenschutz, Ingolstaedter Landstr. 1, 85764 Oberschleissheim, Germany \\ ${ }^{3}$ Institut für Radioökologie und Strahlenschutz, Leibniz Universität Hannover, Herrenhäuser Str. 2, 30419 Hannover, Germany \\ ${ }^{4}$ Université de Lorraine, Campus ARTEM, 54042 Nancy, France
}

Received: 5 April 2019 / Accepted: 4 June 2019

\begin{abstract}
In the past 5 years several projects were launched in FP7 and H2020 with the aim to support competence building in nuclear by fostering education and training (E\&T) initiatives. ENETRAP III, CONCERT, CINCH II, MEET-CINCH, PETRUS and EAGLE deal with advanced E\&T in the fields of radiation protection, nuclear chemistry and geological disposal and the transfer of basic knowledge about ionising radiation, its benefits and risks, to the general public. They were launched with the overall objective of maintaining and extending nuclear know-how and competences in Europe and ensuring sustainable knowledge transfer to current and future generations. This paper describes the aims and achievements of these projects and, based on insights and experiences from these projects, provides some recommendations for future policy support regarding maintaining competences in nuclear industry and research.
\end{abstract}

\section{Introduction}

Several studies show a gap between the current demand for competences in the nuclear sector and the supply thereof. Extrapolated towards the future, this gap is only expected to increase due to a perceived shortage in in-flow to compensate the retirements and additional needs in new developments such as for example the medical area, research and decommissioning.

Within this perspective, attracting new people, maintaining a high level of nuclear competences in different domains and assuring adequate knowledge governance is crucial to ensure (i) future safe use of ionising radiation and (ii) the development of new technologies in a safe way.

One of the main goals of the Euratom research and training programmes is to contribute to the sustainability of nuclear energy by generating knowledge (research) and developing competencies (training). Therefore, the EC has supported several Framework Programme and Horizon 2020 projects which included dedicated work packages (WPs) on the transfer of high-level knowledge and understanding in specific nuclear fields. These projects put their efforts in assessing the current state and needs in E\&T in Europe (or

\footnotetext{
* e-mail: mcoeck@sckcen.be
}

build upon the results of previous projects), identify the appropriate educational practices and technologies to use, coordinate international collaboration and efficient use of available funds, and implement and assess novel E\&T initiatives.

In this paper we focus on general education in radiation protection, geological disposal and nuclear chemistry as well as advanced specialized training in these domains as an essential part to prevent the decline in expertise and to ensure the availability of elevated knowledge, skills and attitudes which can meet the future demands. These are provided in ENETRAP III, CONCERT, CINCH II, MEET-CINCH, PETRUS and EAGLE.

\section{Short presentation of the E\&T projects dealing with radiation protection, nuclear chemistry, geological disposal, and information and communication about ionizing radiation to the general public}

\subsection{ENETRAP III}

Occupational, public and environmental radiation protection (RP) is a major challenge in the industrial, medical and research applications of ionising radiation. As is the 
case with all nuclear expertise, as described above, there is also a trend of a decreasing number of experts in radiation protection. The ENETRAP (European Network on Education and Training in RAdiological Protection) series of three projects started in 2005 and focussed on both the policy and its implementation regarding E\&T in radiation protection, at the European and national level. E\&T in RP has a strong link with the legal requirements. ENETRAP contributed to the revision of the Euratom Basic Safety Standards (BSS - Council Directive 2013/59/Euratom) through the introduction of the new definitions of the Radiation Protection Expert (RPE) and Radiation Protection Officer (RPO) and provided European guidance for Member States implementing this BSS in their national legislations. In addition, it launched an educational network to organise a European Master in Radiation Protection and developed several training courses for RP professionals.

\subsection{CONCERT}

The European Joint Programme for the Integration of Radiation Protection Research CONCERT was launched in 2015 and aims for the development of a joint European strategic research agenda (SRA) in the field of radiation protection. This research agenda is expected to be tailored to societal needs, making full use of newly gained knowledge in all disciplines of life sciences and humanities. It will tackle all relevant sciences and will specifically address E\&T for students and early-stage researchers in order to create and preserve competences needed for a successful and sustainable radiation protection regime in Europe. In order to ensure that human health risks and the possible impact on the environment are better understood and quantified and that radiation protection strategies are optimised, joint national and European research and other co-funded integration activities will be promoted. This will be achieved by an open exchange of knowledge and information between scientists, regulators, stakeholders involved and society as a whole. CONCERT will run over a period of 5 years, until 2020 .

\section{$2.3 \mathrm{CINCH}$ II and MEET-CINCH}

In order to maintain European nuclear competences (operating power plants, radio pharmacy, medicine, disposal of radioactive waste), specific expertise in nuclear and radiochemistry (NRC) is of strategic relevance. In the period 2010-2016, CINCH I and CINCH II (Cooperation in Education in Nuclear Chemistry) were supported within Euratom FP7. The projects aimed at mitigating the special skill-based deficits within nuclear chemistry at Master and Doctorate levels and the decline of qualified staff culminating in founding the NRC network and the NRC European Master.

The H2020 MEET-CINCH project proactively brings the results to the end users at the VET (Vocational Education and Training) level. The nuclear (chemistry) awareness shall be increased and new talents shall be attracted to NRC by developing a Massive Open On-line
Course (MOOC). A modern teaching toolkit based on the flipped classroom concept covering all aspects of NRC is developed and will be available via an e-shop.

\subsection{PETRUS III}

Since 2005, the PETRUS (Programme for Education, Training and Research on Underground Storage) initiative developed a cooperative approach to $\mathrm{E} \& \mathrm{~T}$ in geological disposal of radioactive waste by coordinating the efforts of universities, radioactive waste management organisations, training providers and research institutes. The objective is to ensure the acquirement and continuous improvement of the professional skills by filling the gap between the growing demand and the limited offer for structured education and training in the domain of geological disposal of radioactive waste. Launched as a part of the ENEN II project under FP6 and later granted two times in the frame of FP7, PETRUS proposes an innovative strategy for sharing resources from both academia and industries in the development of reliable E\&T programs.

\subsection{EAGLE}

Together with education and training, information and communication to the general public are key factors in the governance of the exposure to ionizing radiation and its associated risks. Communication about ionizing radiation with the general public has to be further improved. Between 2013 and 2016, the FP7 project EAGLE (Enhancing educAtion, traininG and communication processes for informed behaviours and decisionmaking reLatEd to ionizing radiation risks) aimed at coordinating the information and communication about ionizing radiation at European level. This project made an analysis of the state of the art and the existing needs in education, training and information.

Further in this paper we will describe in more detail the aims, initiatives and achievements of these projects and their suggestions for future approaches. We will conclude with some common needs and recommendations for future European policy support in the domain of education, training and competence building in nuclear.

\section{Project aims, initiatives and main achievements}

\subsection{ENETRAP}

The main goal was to set up actions (i) to better integrate existing E\&T in RP activities and national resources and capacities in Europe in order to counter the decline in both student numbers and training institutions and (ii) to develop more harmonised approaches for E\&T in RP in Europe. This first project, which ran from 2005 to 2007, aimed at overcoming the decline in the RP workforce, promoting crossborder mobility, and providing the necessary competences and expertise for the continued safe use of applications of ionizing radiation in industry, medicine and research. 
One of the main deliverables of this first ENETRAP project was the establishment of an academic consortium which enabled the creation of a European Master in Radiation Protection. The European Master is now a sustainable education programme lead by CEAINSTN.

In the field of training, ENETRAP made an extensive review of the needs, capabilities and (legal) requirements for radiation protection $\mathrm{E} \& \mathrm{~T}$ in all European countries.

It also advised on the integration of on-the-job training (OJT) and work experience (WE) in the complete continuous professional development (CPD) programme of the RP workforce.

The project studied existing national courses as well as international programmes such as the IAEA postgraduate educational course (PGEC) and the Saclaybased RP course and proposed a common curriculum that could be used in all Member States. However, this programme was never fully implemented during the project period.

In ENETRAP II, the Consortium partners worked further on a suitable and acceptable European common training scheme which could serve as high-quality "reference standard" specifically with respect to the training for the radiation protection expert (RPE) and the radiation protection officer (RPO). This scheme could act as basis or mutual recognition of, for examples, RPEs throughout Europe.

The definitions and requirements for RPEs and RPOs were later on adopted in the revised European Basic Safety Standard (EURATOM 2013/59). A reference training curriculum for the RPE was developed and further detailed in terms of learning outcomes in knowledge, skills and competences following the ECVET approaches.

A book was developed by the partners of the ENETRAP II project which contains the basics of the European Radiation Protection Course, which later became available as e-book [1].

Pilot session of the ENETRAP reference training scheme were organised. However, due to a lack of official recognition of the course at European level, the number of participants remained low.

FP7 ENETRAP III brought innovation to existing E\&T approaches in RP developed earlier, such as a European database on E\&T in RP [2], to allow further capacity building in RP. In addition, a guidance document [3] was written for implementing E\&T programmes for RPEs and RPOs, providing essential assistance to all EU Member States who need to transpose the Euratom BSS requirements into their national legislative framework. Next, various pilot sessions of specialised training modules were organised in ENETRAP III according to the ECVET principles. Three modules were aimed at RPEs working in different sectors: power plants and research reactors, the medical area and geological disposal. Another course was aimed at the lecturers itself; this was a unique deliverable in E\&T projects which, up to then, only focussed on the scientist, engineer or workers, but not on the lecturer who needs to demonstrate expert knowledge but also excellent didactic skills and knowledge of the EC credit systems and E\&T approaches.
For all the activities in the ENETRAP project series, the consortium strongly connected with relevant stakeholders, such as end users of ionising radiation, E\&T providers, competent authorities, and to other international organisations, dealing with $\mathrm{E} \& \mathrm{~T}$ in RP. All output from the ENETRAP projects series can be found on the project websites and also on the website of the sustainable EUTERP Foundation (European Training and Education in Radiation Protection Foundation) [4].

During about one decade, the ENETRAP Consortia have experienced a willingness throughout Europe to cooperate in order to strengthen E\&T in RP. However, national legislations are rigid and there seemed no immediate need for the organisation of a European course that meets the European legislation. More interest was shown for the guidance document helping Member States to implement national E\&T programmes in line with the European requirements as set out in the BSS.

Next to development and delivery of appropriate E\&T for different types of RP professionals, it is first of all essential to attract motivated people to the sector.

As a third overall conclusion we can state that retrievability of project results and collaboration between different groups, networks, platforms, etc, can still be optimized.

\subsection{CONCERT}

The CONCERT project under Horizon 2020 aims to contribute to the sustainable integration of European and national research programmes in RP. CONCERT as a cofund action strives to make better use of public R\&D resources and to tackle common European challenges in RP more effectively by joint research efforts in key areas of the EURATOM research programme.

The 5-year (2015-2020) lasting EJP CONCERT successfully interlinks research in all areas of application of ionising radiation throughout Europe. Institutions from almost all EU countries plus Norway and Switzerland have joined forces to pool their expertise and research activities in order to improve RP. CONCERT unites the necessary scientific expertise from the fields of radiobiology, biophysics, epidemiology, medicine, radioecology, and dosimetry among other things at European level and integrates them into joint research projects. The work of CONCERT is based on the current strategic research agendas of the European research platforms MELODI (radiation effects and risks in the low dose range), ALLIANCE (radioecology), NERIS (nuclear and radiological emergency preparedness), EURADOS (dosimetry) and EURAMED (radiation protection in medicine).

CONCERT is guiding RP research in Europe by joint programming, defining joint research priorities and road mapping. This joint effort is performed with a strategic perspective on supporting excellent science, on building and maintaining high competence in radiation science and $\mathrm{RP}$ as well as further promoting integrative and 
multidisciplinary research on a European level. To initiate and fund concerted joint research actions was a crucial step.

CONCERT was running two open RTD calls in 2016 and 2017, respectively, to strengthen the scientific research in strategic priority areas of RP defined by the European radiation research platforms. Within the scope of the calls, universities and research institutions from all over Europe had the opportunity to join forces in consortia and to submit proposals. Altogether nine research projects are currently funded by CONCERT.

Parallel to the research funding activities, CONCERT developed a research agenda in social sciences and humanities in relation to RP that was included as an integral part in the second call for research projects funded by CONCERT.

Further priorities of CONCERT's integrative activities are the development of a joint research roadmap for all RP research sectors, increased E\&T activities for young scientists, and provisions for optimal use of European research infrastructures for RP research.

These integrative activities of CONCERT together with the research funding activities stimulate multidisciplinary work in research and translational work towards societal needs in RP for the general public, workers, patients and the environment [5].

For providing effective E\&T in RP on all levels in Europe in the future, CONCERT recommends:

- to address the need of knowledge, skills and competences as well as to identify gaps in the RP area by building networks and pooling capacities on a European level;

- to reinforce the link between existing E\&T systems and job opportunities in research, medicine and industry by involving stakeholders more closely in competence building processes;

- to provide opportunities for exchange of knowledge (in particular when new research technologies become available) and sharing of experience and training in the use of infrastructures by building networks of universities/networks of professional training for developing joint degree programmes/developing a flexible framework for joint training modules/activities facilitating recognition of competences, promotion of lifelong learning and borderless mobility.

Therefore, E\&T in RP should be promoted as an integral part of all funded research projects on a national and European level.

\section{$3.3 \mathrm{CINCH}$}

The $\mathrm{CINCH}$ project series (cooperation in education in nuclear chemistry) focus on special skills within nuclear chemistry. These skills are of strategic and immediate, importance for the maintenance of nuclear operations and technological options within Europe.

It aims to develop a long-term Euratom fission training scheme to provide a common basis for the fragmented activities in this field. In the first two projects, CINCH and CINCH-II, status quo in NRC education at European universities was assessed, minimum requirements for bachelor, master and postgraduate programs to achieve approved NRC curricula were defined, and a number of theoretical and practical courses were developed using hands-on and e-learning approaches and platforms. The projects were built around the SAT methodology (Systematic Approach to Training). While CINCH-I dealt with the first three phases of the process (analysis, design, development), CINCH-II concentrated on the implementation and evaluation.

The main results of these projects were as follows:

- European Master in Nuclear Chemistry;

- completing a pan-European offer of training courses for the customers from the end users;

- modern E-learning Tools to Enhance Teaching in Nuclear Science, and IV Vision, Sustainability and Awareness;

- development of standards for mutual recognition regarded the quality of training.

Two important outputs were produced: (i) training passport requirements for NRC and (ii) assessment criteria for hands-on courses.

The third consecutive project (MEET-CINCH) addresses the end users in a more focused way offering platforms for immediate practical value [6]. Building on the results of the previous projects, MEET-CINCH will counteract the massive lack of NRC expertise by three actions. A teaching package for high schools and a MOOC on NRC for the chemists of the bachelor level are built in order to attract young persons to the NRC field and convey them its fascination and relevance. Two additional actions focus on vocational training and (university) education. MEET-CINCH develops new E\&T approaches further based on remote teaching and the flipped classroom concept from material generated in the previous projects, such as the NucWik platform and the remote controlled RoboLab experiments [7]. Adapted to the needs of endusers which have been surveyed in the previous projects, MEET-CINCH will provide ECVET course modules in an e-shop. After the end of MEET-CINCH the e-shop will be continuously operated by The European Network on Nuclear and Radiochemistry Education and Training (NRC-network) as part of a sustainable European Fission Training Scheme (EFTS) [8].

CINCH experienced that, in order to counteract the loss of competence in many member states, NRC and RP needs to be made attractive to young persons. Offering E\&T needs to be augmented by sustaining (and financing) stateof-the-art research proving that nuclear topics such as NRC are an active field of research and offer a wide variety of perspectives for a professional carrier.

It is of utmost relevance to finance EU projects dedicated to E\&T. In these projects, the efforts of all member states for NRC education are coordinated, harmonized and symbiotic effects are generated. European universities as well as research centres and partners from industry should be involved.

However, it is just as important to link these E\&T projects and actions to projects and joint programming in basic and applied nuclear research. In the past, this was successfully demonstrated by linking the $\mathrm{CINCH}$ projects 
with ASGARD, ACCEPT, SACCESS and GENIORS. European networking was even strengthened by winning ENEN as a partner in MEET-CINCH. Future links with JOPRAD shall be established taking care of needs defined by IGD-TP.

\subsection{PETRUS}

Rooted in the belief that pooling the efforts and resources of the radioactive waste communities is essential in overcoming the dissipation of knowledge and skills, which in time might jeopardize the safety and security in Europe, the PETRUS initiative was launched in 2005 to improve E\&T in the field of radioactive waste disposal.

During 12 years, PETRUS built a network of trust, mutual support and knowledge transfer among European universities, research centres, and radioactive waste management organisations. A strong bond was created between knowledge providers and end users, encouraging mutual understanding and showing that through better cooperation, it is possible to develop adequate framework for sharing reliable and sustainable knowledge.

The main results from the PETRUS project series were: - The assessment of current and prospective needs of end users and the establishment of the basket of knowledge that students/trainees must acquire to satisfy the immediate and future skills requirements.

- The effective implementation of a European Master's curriculum, based on common courses taught in several partner universities, by using synchronous distance teaching. Using different courses available in the PETRUS partner universities, around $130 \mathrm{~h}$ of lectures have been elaborated.

- The development of framework for qualification-oriented modular training programmes for professionals. PETRUS was pioneer in introducing the ECVET principles from the early beginning of the project. The concept of Professional Development (PD) programmes was developed and skills and competences required by the employers for their present and future staff have been listed. As a practical exercise, two job profiles have been defined and translated in terms of learning outcomes in a "Competency-Based" curriculum encompassing several modules.

- The organisation of PETRUS PhD event to bring together $\mathrm{PhD}$ students and young researchers in radioactive waste disposal, along with professionals and academics. The event provides an opportunity for selected $\mathrm{PhD}$ students to present their works in all areas related to radioactive waste management and disposal. It also gives attendees the opportunity to follow subject-specific lectures prepared by acknowledged academics and experts. Like the PETRUS Master's program, the event continues beyond the life of the project. The fifth edition of the event is expected in July 2019.

- The integration within the ENEN Association that ensures the continuation of the initiative beyond the PETRUS project [9]. Under the umbrella of the ENEN, a dedicated Working Group continues to work in order to reap the full benefits of the efforts and accomplishments achieved so far.

Obviously, much remains to be accomplished in the sphere of E\&T in radioactive waste disposal. The long lasting experience of PETRUS, the learned lessons and the methodologies developed are now sources of inspiration for other European projects such as the ongoing ANNETTE project.

Faced with the delay in the implementation of ECVET system across Europe, the PETRUS project series developed and tested various concepts related to ECVET, leading to several recommendations for the practical implementation. The PETRUS III project elaborated a framework for the learning agreement model (that is essential for the accreditation evaluation), the learner profiles (including the criteria for accepting the students), a model for linking ECVET and ECTS systems, the description of the prototype of the planned program and the Memorandum of Understanding. Further the duties of competent institutions in the procedure of implementation as well as relevant information for the evaluation of the administrative efficiency and transparency as a part of the quality control were drafted.

\subsection{EAGLE}

Education is the first step towards a knowledge-based society and informed decision making. The H2020 EAGLE project set out to identify and disseminate good practices in information and communication processes related to ionizing radiation. For this purpose, the consortium reviewed national and international data, tools and methods as well as institutional work in order to identify education, information and communication needs and coordination possibilities at European level. The lessons learned from the nuclear reactor accident in Fukushima also provided valuable input. Enhancing public understanding of ionizing radiation and facilitating a coordinated communication approach was the main goal of the project.

Moreover, EAGLE fostered a move towards the ideal of citizen-centred communication, including a participative component, bringing together representatives of nuclear actors, users of ionizing radiation, authorities, mass and social media, and informed civil society. The project website contains the scientific reports and records of the many rich interactions [10].

In the final stage of the project, the EAGLE partners wrote a series of recommendations. The recommendations are drawn not only from researchers' analysis, but also, from debate and dialogue with stakeholders from various sectors concerned with managing ionizing radiation risks as well as from civil society and also members of the mass media. In a first step, four national workshops engaged institutional sources and mass media in looking for improvements to the education and communication processes aiming for a population better prepared to take informed decisions relative to ionizing radiation exposure 
situations. Recommendations were translated into good practices answering the major concerns and needs of the public, and can be briefly summarized as follows:

- enhance the role of education on ionizing radiation in schools;

- make available diverse means and opportunities for education and information of the entire population, at any time and not only in a crisis situation;

- build confidence in the institutional sources and maintain it during normal situation;

- adapt the information and communication in order to be understood by the different publics;

- ensure continuous collaboration of institutional sources with mass media for an efficient communication during crisis;

- actively involve scientists and civil society in the communication process.

These recommendations have been validated by other activities of the EAGLE project, the most important being the RICOMET 2016 Conference which gathered over 100 participants from all over the world, and provided the main foundation for the establishment of good practices [11].

Specific recommendations related to the education, training and information material (ETI) are:

- it is not advisable to prepare the ETI materials and activities on a common template in all EU member states;

- contribute to citizens' science projects by organizing or promoting projects about ionizing radiation, sharing information and verifying collected information;

- support science correspondents by offering E\&T related to IR topics including emergencies. In addition, some funds for scholars could be established in order to encourage knowledge gathering in a journalistic population;

- establish "Science Media Centres" as a centralized scientific data service for journalists. Sources can foster this type of resource by becoming dues-paying members and by contributing information and expertise. Similar "Science Education Centres" can be established for teachers.

\section{Common conclusions and recommendations}

Retaining human competences and know-how in the nuclear disciplines and ensuring a high level of education and training (E\&T) remain essential if Europe is to maintain its exemplary record in nuclear activities. Through the projects ENETRAP, EAGLE, CONCERT, CINCH and PETRUS, a large effort was made towards the harmonisation and enforcement of education, training and information in radiation protection, nuclear and radiochemistry, and radioactive waste disposal.

The E\&T projects described in this paper have significantly contributed to the availability of state-ofthe-art course materials and some of them have also developed and implemented new approaches to facilitate and optimize the learning effect. In addition, for example in the case of ENETRAP, contributions to European policy and guidance documents were made.

Some projects have also shown that, on a European level, aspects such as mutual recognition, accreditation and the full implementation of the ECVET system still pose major challenges in all these fields, as well as related nuclear fields.

From the E\&T projects highlighted in this paper, it can be concluded that education of students and early stage scientists and training of nuclear professionals in specialised domains is an essential part of competence building. In addition, general information and communication to enhance public understanding of the origin and applications of radioactivity and the accompanying risks and benefits is of utmost importance and might facilitate attractiveness of the sector for potential new workforce.

Attracting new people to meet the future needs is one of the biggest challenges the nuclear sector is currently faced with. Initiatives that overcome the lack of interested young people and increase awareness about the challenges and innovation possibilities in the nuclear sector, which will contribute to the wellbeing of society, should be supported at European level.

The young generation deserves suitable education and training in the nuclear themes.

Firstly, these E\&T initiatives should be of high quality: the course content should reflect the latest findings from research. Therefore, a direct connection between the research centres and the training centres is advisable. Specifically for vocational $\mathrm{E} \& \mathrm{~T}$ in RP, it is still challenging to translate research outcomes in E\&T programmes. It is of paramount importance that the new findings in research are correctly communicated in terms of impact on the RP system and its practical implementation. A more active approach should be developed to integrate new insights in the initial and continuing training programmes for professionals offered by training institutes, on expert level as well as on the level of the workers exposed to ionising radiation.

Secondly, the content delivery should be optimized according to the learning outcomes and lecturers should not only be experts in their field but should also have excellent didactic skills and be aware of the latest teaching technologies and national and international guidelines and standards regarding ECVET, ECTS and other European E\&T standards and methods.

Project outcomes should be sustainable: many projects described above have liaised with a sustainable platform that will foster the project results and makes them available to the dedicated community. E\&T projects that have not build in such an approach should be encouraged to develop a project repository, complete and easy accessible, so that the outcomes of the project become available to a broader community.

Cross-project outcome management is not yet well established. This would however be of added value to the $\mathrm{E} \& \mathrm{~T}$ stakeholders in the different nuclear domains. It is important to bring together all initiatives developed in both research and E\&T projects, in order to optimize resources, dissemination and participation to courses and to ensure a high-level content and delivery of E\&T various nuclear 
domains in agreement with the European Qualification Framework, Bologna (ECTS) and Copenhagen (ECVET) principles. Next to make available course curricula and/or content, sharing of return on experiences and information about the state of the art in E\&T approaches and tools will optimize the overall quality of E\&T in nuclear. Platforms should be encouraged to work together.

With respect to the various professional actors identified in the Euratom Basic Safety Standard, no specific E\&T guidance documents exist (yet) on the implementation of the E\&T requirements for the following professionals in RP: occupational health services, dosimetry services, emergency workers. European guidance on E\&T for RPEs, RPOs, MPEs and medical professionals were already developed in other European funded projects, such as ENETRAP. In CONCERT, the E\&T WP7 is starting a summary of the needs of other job profiles.

\section{References}

1. P. Massiot, C. Jimonet, European Radiation Protection Course: Basics (EDP Sciences, 2014)

2. E\&T database in radiation protection, http://euterpdb.org
3. European Guidance on the Implementation of the Requirements of the Euratom BSS with respect to the Radiation Protection Expert and the Radiation Protection Officer, ENETRAP III, http://euterp.eu/uploaditems/ENETRA PIII/ENETRAP-III-European-Guidance-Document-amen ded_RAPJES_post_Article_31.pdf

4. European Training and Education in Radiation Protection Foundation (EUTERP), http://euterp.eu/

5. European Joint Programme for the Integration of Radiation Protection Research (CONCERT), http://www.concert-h2020. $\mathrm{eu} /$

6. Cooperation in education in nuclear chemistry (MEETCINCH), https://www.cinch-project.eu/

7. NucWik platform, https://nucwik.wikispaces.com/

8. The European Network on Nuclear and Radiochemistry Education and Training, http://nrc-network.org/

9. Programme for Education, Training and Research on Underground Storage (PETRUS), http://www.enen-assoc. org/en/training/petrus-iii.html

10. Public platform for communication about ionizing radiation (EAGLE), http://eagle.sckcen.be

11. D. Diaconu, M. Constantin, T. Perko, C. Turcanu, C. Mays, G. Baumont, G. Zakrzewska-Kołtuniewicz, A. Miśkiewicz, N. Železnik, M. Kralj, Good practices in public education, training and information on ionizing radiation (2018), ISBN: 978-613-9-84887-4

Cite this article as: Michèle Coeck, Thomas Jung, Mandy Birschwilks, Clemens Walther, Behrooz Bazargan-Sabet, Thomas Perko, Improved expertise in radiation protection, nuclear chemistry and geological disposal, EPJ Nuclear Sci. Technol. 6, 28 $(2020)$ 